\title{
Influence of dysprosium and terbium on structural-mechanical properties of amorphous alloys $\mathrm{Fe}-\mathrm{Nb}-\mathrm{B}-\mathrm{REM}$
}

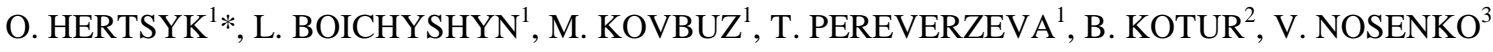 \\ ${ }^{1}$ Department of Physical and Colloid Chemistry, Ivan Franko National University of Lviv, \\ Kyryla i Mefodiya St. 6, UA-79005 Lviv, Ukraine \\ ${ }^{2}$ Department of Inorganic Chemistry, Ivan Franko National University of Lviv, \\ Kyryla i Mefodiya St. 6, UA-79005 Lviv, Ukraine \\ ${ }^{3}$ G.V. Kurdyumov Institute for Metal Physics, National Academy of Sciences of Ukraine, \\ Academician Vernadsky Blvd. 36, UA-03680 Kyiv, Ukraine \\ * Corresponding author. Tel.: +380 32 2600397; e-mail: o_hertsyk@yahoo.com
}

Received October 23, 2014; accepted December 24, 2014; available on-line September 1, 2015

Amorphous alloys $\mathrm{Fe}-\mathrm{Nb}-(\mathrm{REM}=\mathrm{Tb}$ or $\mathrm{Dy})$ near the composition $\mathrm{Fe}_{84} \mathrm{Nb}_{2} \mathrm{~B}_{14}$ were obtained by the melt spinning method and studied in the temperature range of nanocrystallization. It was found that alloying of the basic alloy with Tb or Dy increases the temperature of the first stage of crystallization by approximately $90 \mathrm{~K}$. Alloying with $\mathrm{Tb}$ or Dy also enhanced the microhardness. Both these results support possible application of alloyed Fe-Nb-B-(Tb/Dy) in technical devices operating at high temperature.

Amorphous alloys based on Fe / Rare-earth metals / Nanocrystallization / Microhardness

\section{Вплив диспрозію та тербію на структурно-механічні властивості аморфних сплавів Fe-Nb-B-P3M}

Оксана ГЕРЦИК ${ }^{1}$, Лідія БОЙЧИШИН ${ }^{1}$, Мирослава КОВБУЗ ${ }^{1}$, Тетяна ПЕРЕВЕРЗСВА ${ }^{1}$, Богдан КОТУР ${ }^{2}$, Віктор НOCEHKO ${ }^{3}$

\footnotetext{
${ }^{1}$ Кафедра фізичної і колоїдної хімії, Львівський національний університет імені Івана Франка, вул. Кирила і Мефодія 6, 79005 Львів, Украӥна

${ }^{2}$ Кафедра неорганічної хімії, Львівський національний університет імені Івана Франка, вул. Кирила і Мефодія 6, 79005 Львів, Украӥна

${ }^{3}$ Інститут металофізики ім. Г.В. Курдюмова НАН України, бульв. Академіка Вернадського 36, 03680 ГСП Київ, Україна

* Контактна особа. Тел.: +38032 2600397; e-mail: o_hertsyk@yahoo.com
}

\begin{abstract}
Методом швидкісного гартування $\left(10^{6} \mathrm{~K} / \mathrm{c}\right) 3$ рідкого стану отримано аморфні металеві сплави системи Fe-Nb-B-P3M (P3М = Tb або Dy). Проведено дослідження температурних меж їхньої нанокристалізації і встановлено, що легування базового сплаву Тb чи Dу підвищує температуру першої стадії їх кристалізації приблизно на 90 К. Легування сплаву $\mathrm{Fe}_{84} \mathrm{Nb}_{2} \mathrm{~B}_{14}$ тербісм чи диспрозісм також сприяс підвищенню мікротвердості. Обидва ці результати сприяють використанню легованих сплавів Fe-Nb-B-(Tb/Dy) у технічних пристроях в умовах підвищених температур.
\end{abstract}

Аморфні сплави на основі заліза / Рідкісноземельні метали / Нанокристалізація / Мікротвердість 


\section{Вступ}

Аморфні метали і сплави знаходять щораз більше практичне застосування. Це зумовлено унікальністю їхніх властивостей, які не зустрічаються для звичайних кристалічних металів чи сплавів [1,2].

У процесі отримання аморфних металевих сплавів (АМС) методом швидкого охолодження розплаву в залежності від його елементного складу та швидкості охолодження можуть також утворюватись інтерметалічні сполуки та структурні утворення ближнього порядку [3,4]. АМС є метастабільними системами, нестійкими до процесу кристалізації. Існування аморфного стану обумовлюється сповільненням кінетичних процесів (дифузії атомів) в аморфній фазі, а також наявністю аморфізуючих додатків, що підвищують в'язкість сплаву. Щоб отримати аморфний сплав, розплав повинен переохолодитися до температури, нижчої за рівноважну температуру кристалізації 3 метою подолання енергетичного бар'єру, необхідного для зародження центрів кристалізації [5].

Унаслідок зниження температури під час активного охолодження сплаву підвищується ймовірність виникнення термодинамічно вигідніших кристалічних структур [6], але, водночас, гальмується дифузія атомів. У результаті атомна конфігурація $\epsilon$ нерівноважною і при температурі затвердівання виявляється гомогенно замороженою.

Особливості аморфних металевих сплавів суттєво залежать від їхнього елементного складу. Сплави заліза, які містять бор, забезпечені від корозійного руйнування. Легування бором дозволяє без зниження рівня механічних властивостей скоротити витрати таких металів як $\mathrm{Ni}, \mathrm{Cr}, \mathrm{Mo}, \mathrm{Mn}, \mathrm{V}$. Введення у сплави заліза, ніобію, окрім захисту поверхні, запобігає кристалізації АMC [7]. Мікролегування рідкісноземельними металами (РЗМ) зумовлює формування поверхневих захисних оксидних шарів, стійких до високих температур $\left(\sim 1000^{\circ} \mathrm{C}\right)$. Присутність поверхневих багатокомпонентних плівок з участю РЗМ сприяє стабілізації аморфної фази і затримує розвиток дифузійних процесів, зменшує неоднорідність структури [8], запобігає формуванню небажаних структурних утворень.

Таким чином, легуючі елементи в АМС типу $\mathrm{Fe}-\mathrm{Nb}-\mathrm{B}$ покращують їні властивості, необхідні для практичного застосування.

Метою цієї роботи $є$ дослідження впливу легування базового сплаву $\mathrm{Fe}_{84} \mathrm{Nb}_{2} \mathrm{~B}_{14}$ тербієм або диспрозієм на його термічні та структурні параметри. В обох елементів (Tb, Dy) до $1260 \mathrm{~K}$ зберігається гексагональна гратка типу $\mathrm{Mg}(\alpha-\mathrm{Tb}$, $a=0.356$ нм; $\alpha$-Dy, $a=0.350$ нм). При вищих температурах відбувається перехід у кубічну кристалічну модифікацію типу $\alpha-\mathrm{Fe} \quad(\beta-\mathrm{Tb}$, $a=0.402$ нм; $\beta$-Dy, $a=0.398$ нм). Отже, структурні характеристики обох легуючих металів $\epsilon$ близькими.

\section{Методика експерименту}

Методом гартування з рідкого стану (надшвидкого охолодження розплавів 3 швидкістю $10^{6} \mathrm{~K} / \mathrm{c}$ ) (melt spinning) синтезовано аморфні металеві сплави системи $\mathrm{Fe}-\mathrm{B}-\mathrm{Nb}$, леговані $\mathrm{Tb}$ та Dy, такого складу: $\mathrm{Fe}_{84} \mathrm{Nb}_{2} \mathrm{~B}_{14}, \mathrm{Fe}_{82} \mathrm{Nb}_{2} \mathrm{~B}_{14} \mathrm{~Tb}_{2}, \mathrm{Fe}_{82} \mathrm{Nb}_{2} \mathrm{~B}_{14} \mathrm{Dy}_{2}$. Розплавлену у тиглі шихту під надлишковим тиском інжектували через сопло товщиною 35 мкм та шириною 0.2-2.0 cм на зовнішню поверхню диска-охолоджувача, що обертається 3 швидкістю $40 \mathrm{~m} / \mathrm{c}$.

Криві диференціального термічного аналізу (ДТА) фазових переходів зразків АМС знімали за допомогою синхронного термічного аналізатора STA PT1600 (LINSEIS) (Німеччина) за швидкості зміни температури 10,15 та $20 \mathrm{~K} /$ хв. Основні виміри проводили зі швидкістю 10 К/хв.

Ступінь термоструктурування аморфних металевих сплавів визначали за даними диференціальної скануючої калориметрії (ДСК) (калориметр Perkin-Elmer Pyris 1) зі швидкістю нагрівання 10,15 та $20 \mathrm{~K} / \mathrm{xв}$. Отримані дані оброблені за допомогою стандартного прикладного програмного забезпечення до приладу.

Дифракційні картини вихідних i термічно оброблених аморфних сплавів отримано на дифрактометрі ДРОН-3.0М (Cu $K_{\alpha}$ випромінювання в інтервалі кутів $2 \theta=10-140^{\circ}$, крок $0.04 \%$ ) на кафедрі фізики металів фізичного факультету ЛНУ ім. Івана Франка.

Для випробування на мікротвердість застосовувався прилад ПМТ-3. Для цього алмазну пірамідку під дією вантажу втискували в досліджуваний зразок. Потім діагональ утвореного відбитку вимірювали окулярним мікрометром. Число твердості $\mathrm{H}_{v}$ обчислювали за формулою: $H_{v}=1854 \times P / d^{2},\left[H_{0}\right]=\left[\kappa \Gamma / \mathrm{MM}^{2}\right]$,

де $P$ - вага навантаження, г; $d-$ діагональ відбитка, мкм.

\section{Результати та обговорення}

На дифрактограмах вихідних зразків АМС проявляються гало при кутах $2 \theta=40-50^{\circ}$, характерні для аморфної структури (рис. 1).

Для того, щоб визначити температури фазових переходів АМС, знято диференціальні термічні криві, за якими визначено їхні температури нанокристалізації (рис. 2). 3 порівняння форми ДТА-кривих нелегованого сплаву $\mathrm{Fe}_{84} \mathrm{Nb}_{2} \mathrm{~B}_{14}$ (рис. 2, крива 1) 3 термічними переходами легованих зразків (рис. 2, криві 2, 3) 


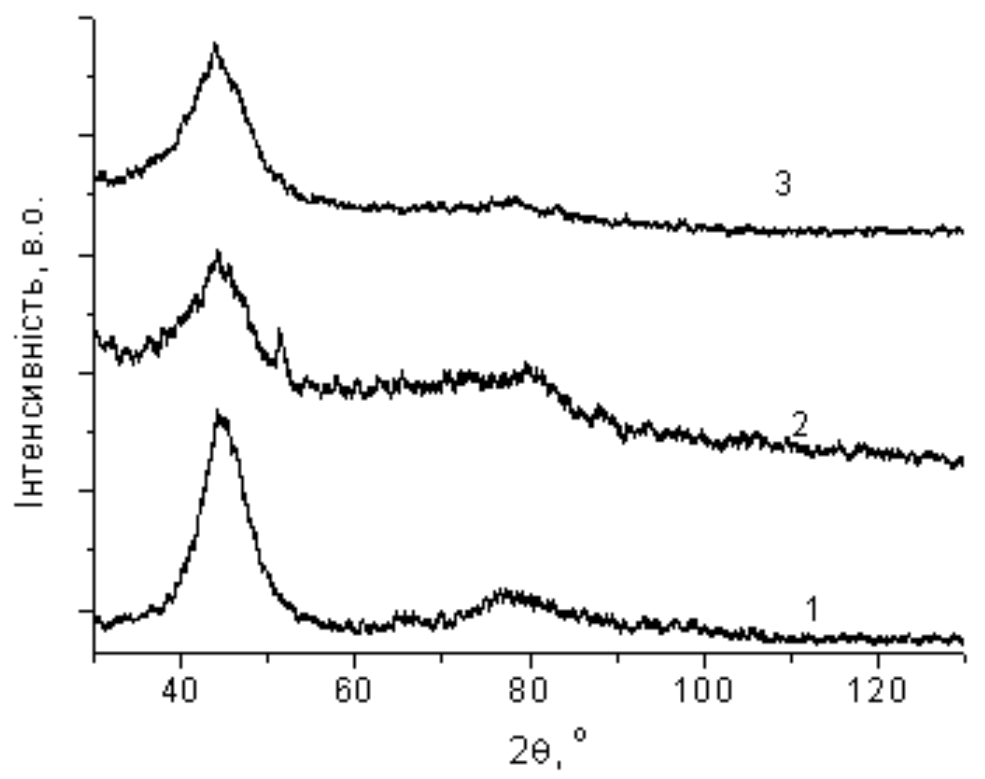

Рис. 1 Дифрактограми вихідних зразків AMC: $1-\mathrm{Fe}_{84} \mathrm{Nb}_{2} \mathrm{~B}_{14}, 2-\mathrm{Fe}_{82} \mathrm{Nb}_{2} \mathrm{~B}_{14} \mathrm{~Tb}_{2}, 3-\mathrm{Fe}_{82} \mathrm{Nb}_{2} \mathrm{~B}_{14} \mathrm{Dy}_{2}$.

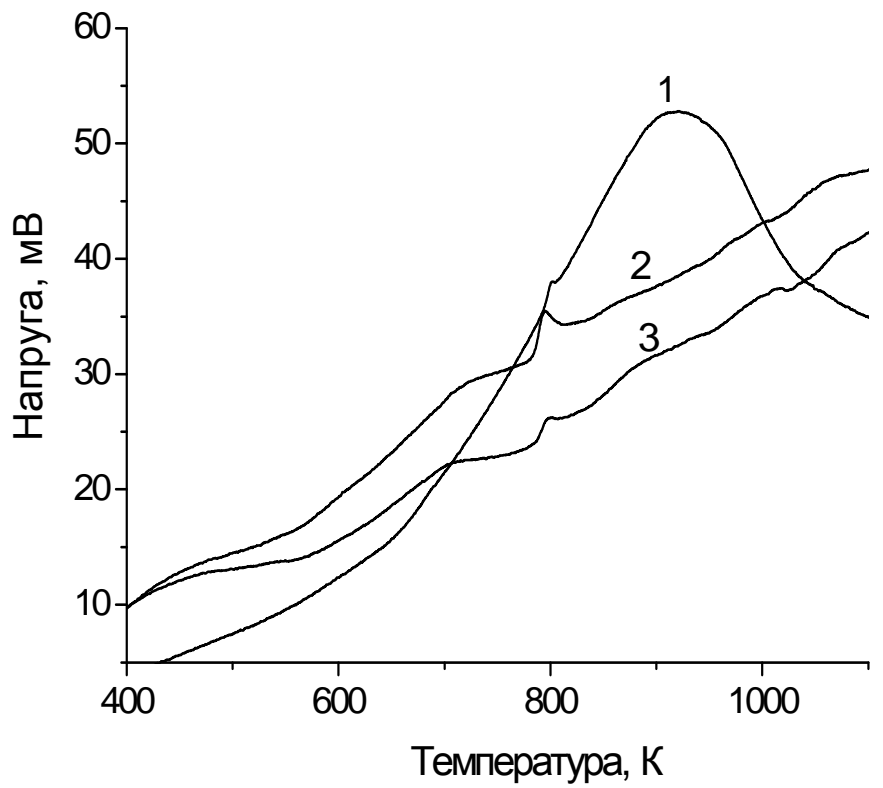

Рис. 2 Криві диференціального термічного аналізу АMC: 1 - $\mathrm{Fe}_{84} \mathrm{Nb}_{2} \mathrm{~B}_{14}, 2-\mathrm{Fe}_{82} \mathrm{Nb}_{2} \mathrm{~B}_{14} \mathrm{~Tb}_{2}$, $3-\mathrm{Fe}_{82} \mathrm{Nb}_{2} \mathrm{~B}_{14} \mathrm{Dy}$.

простежується декілька екзотермічних докристалізаційних стадій 3 малими ентальпійними ефектами i при досягненні температури $800 \mathrm{~K}$ 3'являється екзопік, що свідчить про активне формування нанокристалічної фази.

Результати, одержані методом ДТА, використані для встановлення температурного інтервалу калориметричних досліджень.
Зміна швидкості нагрівання зразків від 10 до $20 \mathrm{~K} / \mathrm{xв}$ в інтервалі $300-850 \mathrm{~K}$ під час ДСК викликає зсув температури екзопіків нанокристалізації у випадку $\mathrm{Fe}_{82} \mathrm{Nb}_{2} \mathrm{~B}_{14} \mathrm{Dy}_{2}$ від 805 до $820 \mathrm{~K}$, при цьому ширина екзопіку звужується, що відповідає прискоренню процесу нанокристалізації (рис. 3). Такий ефект проявляється у всіх трьох AMC. 
Зсув екзопіків у бік вищих температур при збільшенні швидкості нагрівання простежується у всіх досліджених АМС. Взявши до уваги цей температурний зсув, застосовано метод Кіссінджера для обчислення ентальпії активації процесу кристалізації $\left(H_{\text {кр }}\right)$ досліджених зразків. Ми обрали найнижчу швидкість сканування температури нагріву з метою виявлення можливих передкристалізаційних процесів. Форма ДСКкривих усіх трьох сплавів, практично, однакова (рис. 4). Від 350 до $\sim 475 \mathrm{~K}$ нелегований сплав у початковий період поглинає тепловий потік 3 найменшою швидкістю $V_{\text {поч}}=5.4 \cdot 10^{-3} \mathrm{BT} / \Gamma \cdot \mathrm{K}$. На процеси, що відбуваються у легованих сплавах, використовується більше теплоти і $V_{\text {поч }}$ для них у середньому дорівнює $10 \cdot 10^{-3} \mathrm{~B}$ т г К К (табл. 1 ).

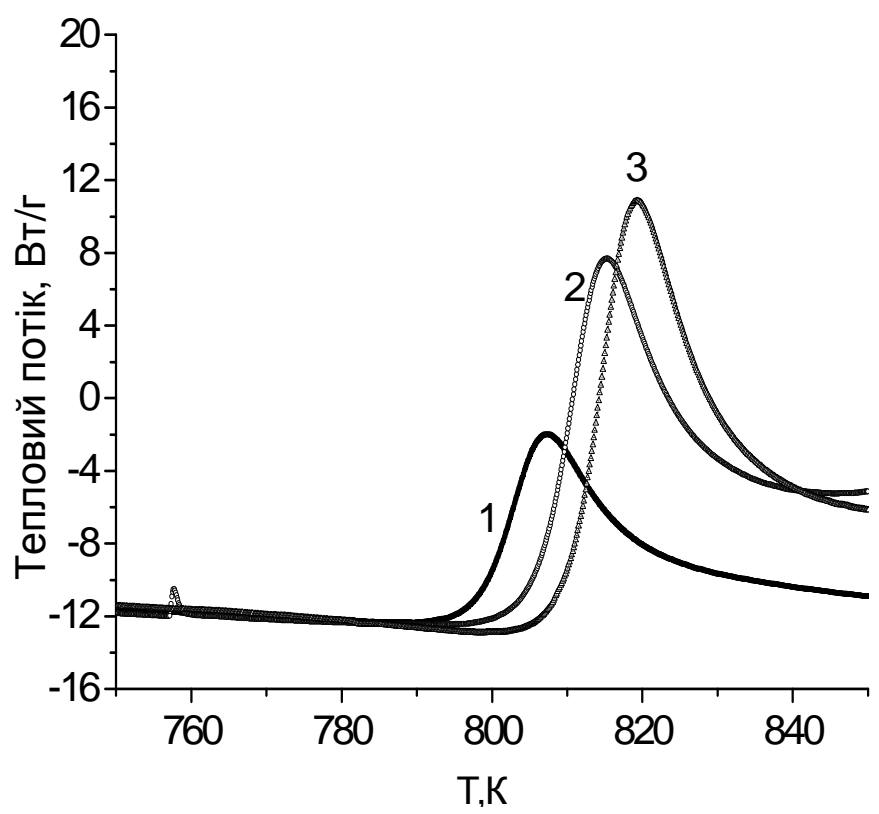

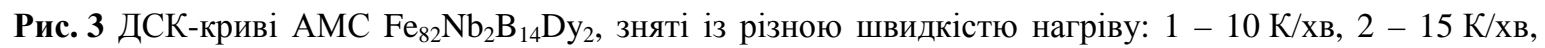
$3-20 \mathrm{~K} / \mathrm{xв}$.

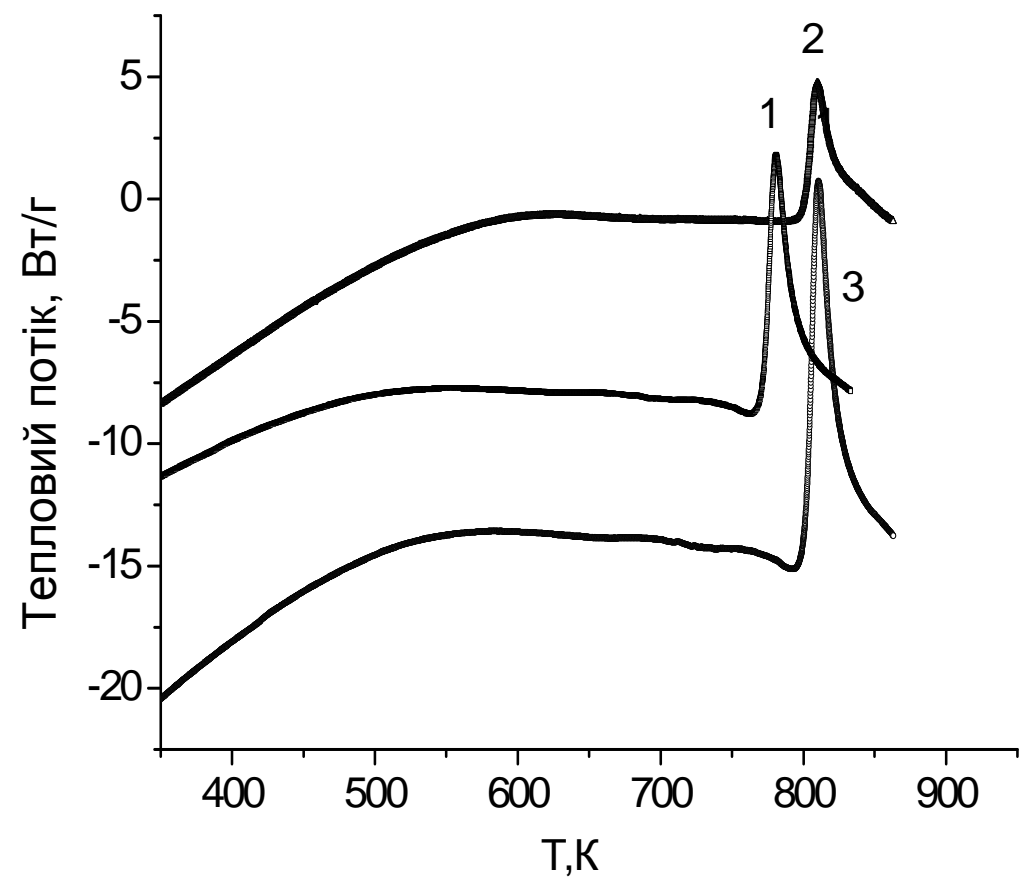

Рис. 4 ДСК-криві зразків АМС: $1-\mathrm{Fe}_{84} \mathrm{Nb}_{2} \mathrm{~B}_{14}, 2-\mathrm{Fe}_{82} \mathrm{Nb}_{2} \mathrm{~B}_{14} \mathrm{~Tb}_{2}, 3-\mathrm{Fe}_{82} \mathrm{Nb}_{2} \mathrm{~B}_{14} \mathrm{Dy}_{2}$, зняті зі швидкістю сканування температури $10 \mathrm{~K} / \mathrm{xв.}$ 
Додавання до сплаву $\mathrm{Fe}_{84} \mathrm{Nb}_{2} \mathrm{~B}_{14}$ тербію або диспрозію помітно підвищує не лише температуру нанокристалізації АМС, але й ентальпію $(H)$ та тепловий ефект $(Q)$ цього процесу (табл. 2). Нанокристали усіх трьох зразків близькі за розміром, що коливається в межах 15-20 нм [9]. У випадку нелегованого сплаву нанокристали найбільшого розміру, хоч наявність $\mathrm{Nb}$ запобігає росту кристалів і його концентрація в усіх трьох зразках однакова (2 ат.\%). Ймовірно, у такому випадку додатково проявляється гальмуючий вплив на дифузію атомів приповерхневих оксидних термостійких шарів [8].

Дифрактограми зразків АМС, відпалених при $823 \mathrm{~K}$ протягом однієї години, тобто при температурі повного формування нанокристалічних фаз, наведені на рис. 5.
Рентгенофазовий аналіз виявив присутність трьох фаз: $\alpha$-Fe та сполук $\mathrm{Fe}_{3} \mathrm{~B}$ i $\mathrm{Fe}_{2} \mathrm{~B}$.

Як було показано (рис. 1), вихідні сплави повністю аморфні, але внаслідок нагріву кристалізуються за механізмом первинної кристалізації, тобто 3 аморфної матриці виділяються нанокристали (рис. 5, табл. 1) ГЦК твердого розчину на основі заліза [10]. Склад нанокристалів $\left(\alpha-\mathrm{Fe}, \quad \mathrm{Fe}_{2} \mathrm{~B}\right)$ відрізняється від вихідного складу сплаву i під час процесу кристалізації аморфна фаза збагачується атомами ніобію та РЗМ.

Ймовірно, що внаслідок зміни співвідношення елементів у аморфній матриці склад наступних кристалічних утворень змінюється [11-13], що в свою чергу зумовлює зміну параметрів гратки.

Табл. 1 Термічні характеристики нанокристалізації AMC Fe-Nb-B-(Tb/Dy) за результатами ДСК.

\begin{tabular}{c|c|c|c|c}
\hline Зразок $\mathrm{AMC}$ & $V_{\text {поч }}, \mathrm{B}$ Т $/ \Gamma \cdot \mathrm{K}$ & $\Delta T, \mathrm{~K}^{*}$ & $T_{\text {поч }}, \mathrm{K}^{* *}$ & $7, \mathrm{HM}$ \\
\hline $\mathrm{Fe}_{84} \mathrm{Nb}_{2} \mathrm{~B}_{14}$ & $5.4 \cdot 10^{-3}$ & $480-700$ & $80 \pm 4$ & 20 \\
$\mathrm{Fe}_{82} \mathrm{Nb}_{2} \mathrm{~B}_{14} \mathrm{~Tb}_{2}$ & $9.3 \cdot 10^{-3}$ & $575-775$ & $809 \pm 2$ & 17 \\
$\mathrm{Fe}_{82} \mathrm{Nb}_{2} \mathrm{~B}_{14} \mathrm{Dy}_{2}$ & $10.8 \cdot 10^{-3}$ & $510-700$ & $810 \pm 2$ & 15 \\
\hline
\end{tabular}

* - температурний інтервал стаціонарного стану,

** - температура початку нанокристалізації.

Табл. 2 Термічні характеристики нанокристалізації AMC Fe-Nb-B-(Tb, Dy) за результатами ДСК.

\begin{tabular}{c|c|c|c|c}
\hline Зразок $\mathrm{AMC}$ & $T_{\text {поч }}, \mathrm{K}$ & $T_{\text {відп }}, \mathrm{K}$ & $H_{\text {акт }}, \mathrm{eB}$ & $Q$, Дж/Г \\
\hline $\mathrm{Fe}_{84} \mathrm{Nb}_{2} \mathrm{~B}_{14}$ & 718 & 823 & 2.56 & 32.72 \\
$\mathrm{Fe}_{82} \mathrm{Nb}_{2} \mathrm{~B}_{14} \mathrm{~Tb}_{2}$ & 809 & 823 & 5.18 & 66.20 \\
$\mathrm{Fe}_{82} \mathrm{Nb}_{2} \mathrm{~B}_{14} \mathrm{Dy}_{2}$ & 810 & 823 & 5.04 & 68.10 \\
\hline
\end{tabular}

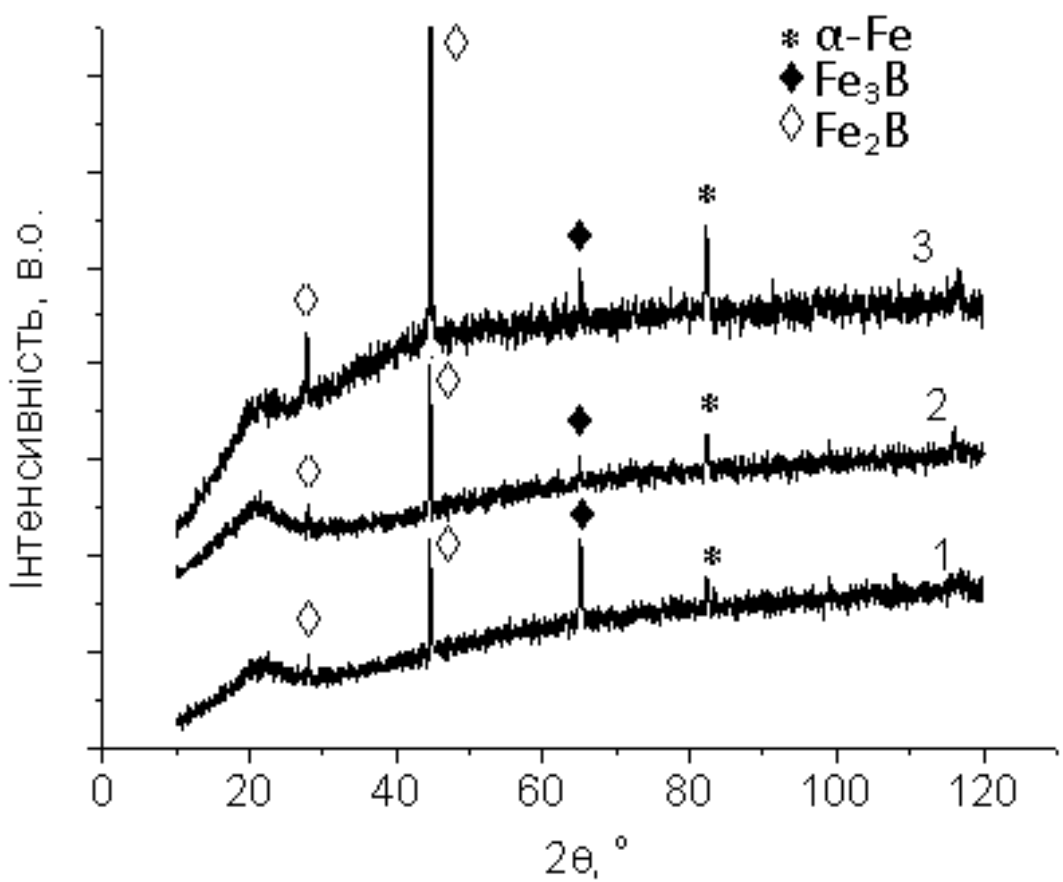

Рис. 5 Дифрактограми аморфних металевих сплавів, відпалених протягом 1 год при $T=823$ К: $1-\mathrm{Fe}_{84} \mathrm{Nb}_{2} \mathrm{~B}_{14}, 2-\mathrm{Fe}_{82} \mathrm{Nb}_{2} \mathrm{~B}_{14} \mathrm{~Tb}_{2}, 3-\mathrm{Fe}_{82} \mathrm{Nb}_{2} \mathrm{~B}_{14} \mathrm{Dy}_{2}$. 
Табл. 3 Механічні характеристики вихідних і відпалених 1 год при $T=823$ К аморфних сплавів.

\begin{tabular}{|c|c|c|c|c|c|c|}
\hline Сплав & $T, \mathrm{~K}$ & $H_{v}$, ГПа & $\Delta H_{\mathrm{v}}, \Gamma \Pi а$ & $r \cdot 10^{3}, \mathrm{HM}^{*}$ & $d, \mathrm{HM}$ & $\Delta d$, нм \\
\hline $\mathrm{Fe}_{84} \mathrm{Nb}_{2} \mathrm{~B}_{14}$ & $\begin{array}{l}298 \\
823\end{array}$ & $\begin{array}{l}8.2 \\
8.8\end{array}$ & 0.6 & - & $\begin{array}{l}20 \\
23\end{array}$ & 0.3 \\
\hline $\mathrm{Fe}_{82} \mathrm{Nb}_{2} \mathrm{~B}_{14} \mathrm{~Tb}_{2}$ & $\begin{array}{l}298 \\
823\end{array}$ & $\begin{array}{l}13.4 \\
13.9\end{array}$ & 0.5 & 0.225 & $\begin{array}{l}17 \\
19\end{array}$ & 0.2 \\
\hline $\mathrm{Fe}_{82} \mathrm{Nb}_{2} \mathrm{~B}_{14} \mathrm{Dy}_{2}$ & $\begin{array}{l}298 \\
823\end{array}$ & $\begin{array}{l}12.2 \\
12.6\end{array}$ & 0.4 & 0.228 & $\begin{array}{l}15 \\
19\end{array}$ & 0.4 \\
\hline
\end{tabular}

* - радіус атома легуючого елемента.

Леговані РЗМ сплави мають вищу термічну стабільність (рис. 4, табл. 1). Середній розмір зерен легованих $\mathrm{AMC}$ на 3-5 нм менший. Одногодинний відпал при температурі першої стадії кристалізації приводить до певного збільшення розміру нанокристалічних часточок, які мають здатність зміцнювати аморфну матрицю.

Збільшення мікротвердості $\left(H_{v}\right)$ легованого диспрозієм сплаву в порівнянні 3 базовим $\mathrm{Fe}_{84} \mathrm{Nb}_{2} \mathrm{~B}_{14}$ зростає на 4 ГПа, у випадку $\mathrm{Fe}_{82} \mathrm{Nb}_{2} \mathrm{~B}_{14} \mathrm{~Tb}_{2}$ - на 5.2 ППа (табл. 3). Приріст мікротвердості після відпалу коливається в межах 0.4-0.6 ГПа.

\section{Висновки}

1. При переході $\mathrm{Fe}_{84} \mathrm{Nb}_{2} \mathrm{~B}_{14} \rightarrow \mathrm{Fe}_{82} \mathrm{Nb}_{2} \mathrm{~B}_{14} \mathrm{~Tb}_{2} \rightarrow$ $\mathrm{Fe}_{82} \mathrm{Nb}_{2} \mathrm{~B}_{14} \mathrm{Dy}_{2}$ інтенсивність піків при $2 \theta=28^{\circ}, 44^{\circ}$ i $83^{\circ}$ зростає, що свідчить про підвищення в цих сплавах кількості фаз $\alpha$-Fe та $\mathrm{Fe}_{2} \mathrm{~B}$.

2. Уведення в аморфний сплав $\mathrm{Fe}_{84} \mathrm{Nb}_{2} \mathrm{~B}_{14} 2$ ат.\% $\mathrm{Tb}$ aбо Dy підвищує температуру нанокристалізації сплавів приблизно на 90 K $(718 \rightarrow 810 \mathrm{~K})$, що дозволяє використовувати леговані аморфні сплави при вищих температурних експлуатаційних режимах.

3. Природа легуючого елемента чинить більший вплив на підвищення мікротвердості в порівнянні 3 одногодинним відпалом при $T=823 \mathrm{~K}$.

\section{Літературні посилання}

[1] А.Л. Бурин, Ю.О. Каган, Ж. эксп. теор. физ. 109(1) (1996) 299-324.

[2] А.А. Щерецкий, В.Л. Лахненко, В.С. Шумихин, В.А. Соловьева, Электронная микроскопия и прочность материалов. Сер. : Физическое материаловедение, структура и свойства материалов. 17 (2010) 57-65.

[3] D.S. dos Santos, D.R. dos Santos, Non-Cryst. Sol. 304(1-3) (2002) 56-63.

[4] S. Thongmee, C. Issro, S. Roongkeadsakoon, P. Winotai, I.M. Tang, Mod. Phys. Lett. B 13(6-7) (1999) 175-179.

[5] I.B. Kutsenok, S. Kunze, B.V. Mikhailovsky, V.A. Geiderikh, Ber. Bunsengesellsch. Phys. Chem. 102(9) (1998) 1116-1122.

[6] В.В. Савін, Е.Ю. Костенко, О.Б. Коновалов, Фіз. хім. тв. тіла 7(4) (2006) 670-672.

[7] О. Герцик, М. Ковбуз, Л. Беднарська, Б. Котур, І. Козак, Н. Кавчак, Фіз.-хім. механ. матер. Спец. вип. 3 (2002) 189-194.

[8] A. Chrobak, D. Chrobak, G. Heneczok, P. Kwapulinski, Z. Kwolek, M. Karolus, Mater. Sci. Eng. A 382 (2004) 401-406.

[9] A. Chrobak, V. Nosenko, G. Haneczok, L. Boichyshyn, M. Karolus, B. Kotur, Non-Cryst. Sol. 357(1) (2011) 4-9.

[10] Л. Бойчишин, М. Ковбуз, О. Герцик, В. Носенко, Б. Котур, Физ. тв. тела 55(2) (2013) 209-212.

[11] Г.Е. Абросимова, А.С. Аронин, И.И. Зверькова, А.Ф. Гуров, Ю.В. Кирьянов, Физ. тв. тела 40(1) (1998) 10-16.

[12] M.A. Popescu, Non-Cryst. Sol. 169 (1994) 155-159.

[13] V.A. Blagojevic, D.M. Minic, T. Zah, D.M. Minic, Intermetallics. 19 (2011) 1780-1785. 